\title{
Um recorte transversal da objetivação reificante na relação terapeuta/cliente
}

\author{
A transversal cut of the objectivization \\ reifying the doctor/patient relationship
}

Everaldo Tôrres Barbosa 1 Abstract It was not by mere chance that the two
great, mature works of Marx seeking to describe
capitalist society and to undrape its fundamental
character started with analyzing the goods. In
fact, in this stage of the evolution of mankind,
there is not one problem not leading us ultimately
to this question, whose solution however cannot
be found by trying to solve the structural enigma
of the goods. When looking into the relation be-
tween health professionals and patient, whose in-
terpretation of biomedicine sustained and demar-
cated objectivized and mechanicist functions, we
observe that Marx' search for understanding cap-
italism led basically to the same conceptwe find in
the merchantilist relation between doctor and pa-
tient, coined by rationalism.
Key word Alienation, Kapital, Doctor/Patient
relationship
Resumo Não é por acaso que as duas grandes obras da maturidade de Marx, cujo objetivo é descrever o conjunto da sociedade capitalista $e$ pôr a nu o seu caráter fundamental, começam por uma análise da mercadoria. Com efeito, nesta etapa da evolução da humanidade não há problema que não nos remeta, em última análise, para esta questão, e cuja solução não deva ser procurada na solução do enigma da estrutura da mercadoria. Quando nos debruçamos sobre a relação dos profissionais da saúde com o cliente, cujo olhar da biomedicina sustentou e demarcou funções objetivadas e mecanicistas, observamos que a busca de compreensão de Marx diante do capitalismo não deixa de ter a mesma concepção mercantilista nesta relação, cunhada de racionalista. Palavras chave Alienação, Capitalismo, Relação terapeuta $x$ cliente

1 Departamento de 


\section{Introdução}

Cada coisa útil, como ferro, papel, etc., pode ser considerada, sob duplo aspecto, segundo qualidade e quantidade. Cada um desses objetos é um conjunto de muitas propriedades e pode ser útil de diferentes modos, das diversas maneiras de usar as coisas, e a invenção das medidas, socialmente aceitas, para quantificar as coisas úteis. A variedade dos padrões de medidas das mercadorias decorre da natureza diversa dos objetos a medir e também de convenção.

A utilidade de uma coisa faz dela um valor de uso. Mas, essa utilidade não é algo aéreo. Determinada pelas propriedades materialmente inerentes à mercadoria, só existe através dela. A própria mercadoria, como ferro, trigo, diamante, atendimento clínico elou ambulatorial (acréscimos meus) etc., é, por isso, um valor de uso, um bem. Esse caráter da mercadoria não depende da quantidade de trabalho empregado para obter suas qualidades úteis. Ao se considerarem valores de uso, sempre se pressupõem quantidades definidas, como uma dúzia de relógios, um metro de linho, uma tonelada de ferro, trinta atendimentos clínicos/dia (acréscimos meus) etc. Os valores de uso fornecem material para uma disciplina específica. $\mathrm{O}$ valor de uso só se realiza com a utilização ou o consumo 1 .

É evidente que o ser humano, por sua atividade, modifica do modo que lhe é útil a forma dos elementos naturais. Modifica, por exemplo, a forma da madeira, quando ele faz uma mesa. Mas, logo que se transforma em mercadoria, torna-se algo ao mesmo tempo perceptível e impalpável.

O caráter misterioso que o produto do trabalho apresenta ao assumir a forma de mercadoria de onde provém? Dessa própria forma, claro. A igualdade dos produtos do trabalho como valores; a medida, por meio da duração, do dispêndio da força humana de trabalho toma a forma de quantidade de valor dos produtos do trabalho; finalmente as relações entre os produtores, nas quais se afirma o caráter social dos seus trabalhos, assumem a forma de relação social entre os produtos do trabalho'.

Uma relação social definida, estabelecida entre os homens, assume a forma fantasmagórica de uma relação de coisas. Para encontrar um símile, temos de recorrer à região nebulosa da crença. Aí, os produtos de cérebro humano parecem dotados de vida própria, figuras autônomas que mantêm relações entre si e com os seres humanos. É o que ocorre com os produtos de mão humana, no mundo das mercadorias. Marx chama isto de fetichismo, que está sempre grudado aos produtos do trabalho, quando são gerados como mercadorias. É inseparável da produção de mercadorias, é uma qualidade social própria do trabalho que produz mercadorias. A mercadoria passa a ter uma utilidade, uma função, uma necessidade, chegando a ocupar uma posição criada culturalmente. A coisa em si passa a ter uma outra textura diferente dela mesma. Nós desejamos não o produto, mas o que ele representa, como a marca, isto é, a grife. Não é de fato a mercadoria, ou o objeto em si, mas a sua representação, aquilo que ela faz sentido no imaginário das pessoas, não aquilo que as pessoas sonham, mas o que a marca representa. $O$ sonho não é a pessoa, mesmo que ela se sinta bem com a roupa, o carro, a casa na praia, o calção de praia, os óculos, o médico, o professor, mas, o significante do significado.

A dominação, ou seja, a probabilidade de encontrar obediência a um determinado mandato, pode fundar-se em diversos motivos de submissão. Pode depender diretamente de uma constelação de interesses, ou seja, de considerações utilitárias de vantagens e inconvenientes por parte daquele que obedece. Pode também depender do mero "costume", do hábito cego de um comportamento inveterado. Ou pode fundar-se, finalmente, no puro afeto, na mera inclinação pessoal do súdito. Não obstante, a dominação que repousasse apenas nesses fundamentos seria relativamente instável. Nas relações entre dominantes e dominados, por outro lado, a dominação costuma apoiar-se internamente em bases jurídicas, nas quais se funda a sua "legitimidade". O abalo dessa crença na legitimidade costuma acarretar conseqüências de grande alcance ${ }^{2}$. Podemos perceber que a representação da relação entre as pessoas passa a ter um valor de relacionamento, em que um dos indivíduos se coloca num patamar de obediência, submete-se ao outro. Quando eles estão se relacionando, não conseguimos perceber ou observar uma comunicação, mas alguém deve obedecer ao outro, que lhe é superior. E ser superior é diferente de ser inferior, e o inferior é inferior por não ser superior, e este processo exige obediência, exatamente para compor o processo de relacionamento. Não são pessoas, mas objetos vestidos de funções que não se complementam, mas que se opõem. Existe uma determinação que deve ser seguida à risca. 
Não é por acaso que as duas grandes obras da maturidade de Marx, cujo objetivo é descrever o conjunto da sociedade capitalista e pôr a nu o seu caráter fundamental, começam por uma análise da mercadoria. Com efeito, nesta etapa da evolução da humanidade não há problema que não nos remeta, em última análise, para esta questão e cuja solução não deva ser procurada na solução do enigma da estrutura da mercadoria. É evidente que o problema só pode elevar-se a este grau de generalidade quando colocado com a grandeza e profundidade que atinge nas análises de Marx, quando o problema da mercadoria não aparece apenas como um problema particular nem mesmo como o problema central da economia tomada como uma ciência particular, mas como o problema central, estrutural da sociedade capitalista em todas as suas manifestações vitais. Só assim é possível descobrir na estrutura da relação mercantil o protótipo de todas as formas de objetividade e de todas as formas correspondentes de subjetividade na sociedade burguesa. Observamos que a subjetividade é restrita à objetividade. $\mathrm{O}$ sonho não é da pessoa, mas da objetivação. Ela determina a qualidade e a quantidade de imaginação. Reduz o sujeito a um objeto, que terá necessariamente tais e tais comportamentos. Toda a expressão deste indivíduo é medida, quantificada, pesada, analisada. É, portanto, um comportamento esperando dentro de um padrão preestabelecido, e dentro de uma determinada classe social. A fala, a expressão, a linguagem, a atitude, o comportamento, o corpo, a postura física passam a ter um mesmo e só elemento daquela classe social, ou daquele estamento, as pessoas são previsíveis.

Já muitas vezes se realçou a essência da estrutura mercantil, que assenta no fato de uma ligação, uma relação entre pessoas, tomar o caráter de uma coisa, e ser, por isso, de uma objetividade ilusória que, pelo seu sistema de leis próprio, aparentemente rigoroso, inteiramente fechado e racional, dissimula todo e qualquer traço de essência fundamental: a relação entre homens. Não vamos analisar neste artigo o quanto se tornou central para a própria teoria econômica nem as conseqüências que teve para as concepções econômicas do marxismo vulgar o abandono deste ponto de partida metodológico. Limitar-nos-emos a chamar a atenção - pressupondo as análises econômicas de Marx, para as questões fundamentais que decorrem, por um lado, do caráter fetichista da mercadoria como forma de objetividade, por outro, do comportamento do sujeito que lhe está coordenado. Reduzir o sujeito ao objeto. Reificação.

A questão do fetichismo é específica da nossa época e do capitalismo moderno. Buscamos evidenciar de que forma e em que medida o tráfico mercantil e as suas conseqüências estruturais são capazes de influenciar toda a vida, exterior como interior, da sociedade, portanto, do indivíduo. E ainda que valores foram introjetados e assimilados na formação e exercício do terapeuta que objetiva a doença no doente, e trata a doença como algo objetivado no indivíduo. O mapa passa a ser o território, e as ações para se chegar no objetivo são traçadas de formas inequívocas; diagnosticamos, damos nome à doença e um destino ao doente. Ele deverá cumprir todas as prescrições, seguir todas as orientações. É uma objetivação que se exterioriza no indivíduo, um valor de uso do prognóstico, ele deverá seguir exatamente a prescrição, e a pessoa mesmo entorpecida por ter de interiorizar coisas, comportamentos, atitudes, cuidados que um outro determina. Não existe historicidade nesta dinâmica, não existe intertexto, não existe interface. È uma relação linear binária, tipo estímulo-resposta. O indivíduo doente é reificado numa visão transversal do seu processo histórico, isto é, nada que venha antes ou depois da abordagem terapêutica interfere ou influencia a conduta do terapeuta. Apenas a doença é a presentificação. Construímos uma abordagem de inserção, portanto, de interferência na vida do indivíduo doente, como se estivéssemos excluindo algo do agora, para restituirmos um outro agora, com uma qualidade da melhora do quadro. Nada que seja da vida íntima da pessoa doente nos interessa, a doença é a instituição que nos aponta para saídas e soluções.

É um processo de troca, como se estivéssemos trocando mercadorias de valores de uso. A técnica e os conhecimentos do terapeuta e os estágios da doença. O terapeuta tem uma mercadoria, em que vende como saúde, e o doente tem a mercadoria denominada de doença. E efetivamos uma troca, obviamente com um preço útil.

Marx descreve o fenômeno fundamental da reificação nos seguintes termos: o caráter misterioso da forma mercantil consiste, pois, simplesmente, no fato de ele revelar aos homens características sociais do seu próprio trabalho como propriedades sociais naturais dessas coi- 
sas e, por conseguinte, também a relação social entre os produtores e o conjunto do seu trabalho, como relação social exterior a eles, relação entre objetos.

Deste fenômeno estrutural fundamental há que reter, antes do mais, o que faz com que o homem se oponha à sua própria atividade, ao seu próprio trabalho, como algo de objetivo, independente dele e que o domina pelas suas leis próprias, estranhas ao homem. Isto se verifica tanto no plano objetivo quanto no subjetivo. Objetivamente, surge um mundo de coisas acabadas e de relações entre coisas (o mundo das mercadorias e do seu movimento de mercado). Subjetivamente, a atividade do homem, numa economia mercantil realizada, objetiva-se em relação a ele, torna-se uma mercadoria regida pela objetividade das leis sociais naturais estranhas aos homens e deve efetuar os seus movimentos tão independentemente dos homens como qualquer bem destinado à satisfação de necessidades, que se tornou coisa mercantil.

Não é o terapeuta que está presente, mas a técnica. Não é o indivíduo doente que está presente, mas a sua doença, como se ela fosse uma entidade destituída do portador, e o terapeuta fosse um indivíduo destituído de afeto, que não pode olhar o doente e se envolver com compaixão. Cada um no seu papel conhecido, exigido, e nada além disso. As instituições responsáveis pela atitude ética de cada um exigem e pedem atitudes de efetividades. É uma máquina atendendo outra máquina. Os tempos modernos são agora estes, seres humanos agindo como verdadeiras máquinas, destituídos de afetos, de desejos, de compulsões e sonhos; as escolas formam verdadeiros andróides e os clientes agem também como tais, não nos interessam seus sonhos, nem queremos saber aonde moram. A sua identidade é a sua doença.

A decomposição racional, pelo cálculo, do processo de trabalho, elimina a necessidade orgânica das operações parciais reciprocamente relacionadas e congregadas no produto de uma unidade. A unidade do produto como mercadoria não coincide já com a sua unidade como valor de uso. Com a capitalização radical da sociedade, a automatização técnica das manipulações parciais e produtivas exprime-se, também economicamente, pela autonomização das operações parciais, pela relativização crescente do caráter mercantil de um produto nas diferentes etapas da sua produção.

Para Marx, cria-se um estado tal que os homens se apagam perante o trabalho: o pêndulo do relógio tornou-se a medida exata da atividade relativa de dois operários, como o é a velocidade de duas locomotivas. Então, já não se diz que uma hora de trabalho de um homem vale uma hora de outro homem, mas, antes, que um homem por uma hora de outro homem por uma hora. O tempo é tudo; o homem já não é nada; é, quando muito, a carcaça do tempo, exceto o montante da sua produção que tem valor de uso, valor de equivalência (o seu produto pode ser trocado por um outro produto de utilidade diferente), e valor de troca. Só a quantidade decide tudo, são 16 fichas para atender somente 16 doentes. O próprio tempo perde o seu caráter qualitativo, mutável, fluido: fixa-se num continuum exatamente delimitado, para cada doente 15 minutos de consulta, é um quantitativo mensurado pelo trabalhador (terapeuta), trabalho realizado pelo trabalhador, reificado, mecanicamente objetivado, separado com precisão do conjunto da personalidade humana num espaço.

A mecanização da produção faz deles, também neste aspecto, átomos isolados e abstratos, que a realização do seu trabalho já não congrega de forma imediata e orgânica e cuja coesão é, antes, exclusivamente e em grau sempre crescente mediatizada pelas leis abstratas do mecanismo em que estão integrados. O terapeuta trata da dor lombar, e não diferencia esta dor lombar quando ele se depara com outros dez indivíduos portando dores lombares, são todos, apenas, dores lombares. E o cliente assume a identidade de dor lombar, e aceita ser tratado como tal. Torna-se uma relação em escala de produção, escoando a produção de medicamentos ou qualquer outra atividade de cunho terapêutico. Como por exemplo: uma técnica que é boa para isto e para aquilo, independentemente de ser aplicada em fulano, sicrano e beltrana.

Esta objetivação racional dissimula a coisidade imediata, qualitativa e quantitativa, de todas as coisas. Como aparecem a todos, sem exceção, como mercadorias, os bens de uso adquirem uma nova objetividade, uma nova coisidade que não tinham na época de trocas meramente episódicas e que destrói a sua coisidade própria e originária, que a faz desaparecer. Marx nos diz que a propriedade privada aliena não só a individualidade dos homens, mas também das coisas. O cliente não tem nada a ver com a doença; são duas coisas que não se combinam e precisam ser separadas. Para o terapeuta, a doença é sinal de lucro, ele investe no 
conhecimento da doença, mas não no doente. O terapeuta coisifica o doente pela doença, ele trata da doença como um mal a ser extirpado, mesmo que este ato seja um seio de uma mulher com 26 anos de idade. E os eventos científicos passam a ter nomes de doenças ou de especialidades.

Marx descreve este aumento do poder da reificação de forma penetrante. Contentemonos com um exemplo: no capital usurário, este fetiche automático está, por conseguinte, em evidência na sua forma pura, valor que se valoriza a si mesmo, dinheiro faz filhos, e não traz já, sob esta forma, nenhuma marca de nascença. A relação social está completada como relação de uma coisa, do dinheiro em capital, só se mostra aqui a sua forma desprovida de conteúdo... Assim, criar valor, dar juros como a macieira dá maçãs, tornou-se inteiramente uma propriedade do dinheiro.

A alienação é um fenômeno que apresenta múltiplas formas de objetivação no transcurso da história. Possui sua gênese na história, com o surgimento da divisão social do trabalho e da propriedade privada. No entanto, seus efeitos não podem ser reduzidos a essas determinações econômico-sociais. Com o tempo, alienação se autonomiza como fenômeno e suas causalidades desaparecem socialmente, produzindo processos sociais que possuem uma inércia própria e tendem a ficar imunes às diversas transformações sociais.

A alienação introduz uma refração fundamental nas relações dos homens entre si e dos homens com a natureza. Sob seus influxos, dáse uma ruptura essencial no processo de formação dos sujeitos em suas necessárias interações com os objetos que lhes são circundantes. Rompe-se a relação entre sujeito e objeto, que sempre têm uma definição relacional recíproca. Os sujeitos são apartados dos objetos, que se autonomizam diante dos sujeitos, invertendo a condição ativa e particular dos elementos desse processo e instaurando-se a subordinação dos sujeitos aos objetos. Os sujeitos, possuidores de capacidade volitiva e atividade criativa, perdem o controle sobre si mesmos e sobre os produtos da sua atividade. Assim, os homens são, literalmente, rebaixados de sua condição de sujeitos à condição de simples objetos. Não mais conseguem perceber e reconhecer as formas sociais, em que estão imersos, como o resultado de sua própria vontade e atividades sociais. Os homens passam a ignorar, portanto, o caráter dos vínculos que estabele- cem entre si e configuram o conjunto de sua vida social e as relações produtivas que mantêm com a natureza ${ }^{3}$.

Mas se pensarmos que o poder se expressa em nossa sociedade mundial contemporânea muito mais como massificação, homogeneização, vamos ver que o que nos liberta é a diferenciação, a singularização, um construtivismo somático-existencial, passo a passo, como nos propõe Stanley Keleman. Essa lógica da multiplicidade rompe com as hierarquias caracterológicas e proporciona uma linguagem descritiva para a diferença e seus modos de operar o presente. Essa posição recoloca a clínica no campo da filosofia, oferece à filosofia um método encarnado que, definitivamente, encerra as questões de corpo e mente, ilumina na biologia a questão de como a experiência continua o trabalho da evolução 4 .

O caráter manifesta uma organização consistente, uma lógica interna com seus modos próprios de expressão, emoção e ação. É o comportamento pelo qual você é reconhecido. Sua estrutura é o sumo da história emocional pessoal, assim como determinismo genético universal. O caráter, como toda estrutura, tem camadas que funcionam para sobrevivência e manutenção, proteção e nutrição, crescimento e reprodução. Essas camadas podem ser identificadas no cérebro como tronco cerebral, mesencéfalo e córtex, e, em todo o corpo, como pele, músculo, vísceras, líquidos e ossos.

Sentimentos resultam de pulsações celulares, metabolismos, correntes citoplasmáticas, motilidade interna. Para alcançar satisfação organísmica, os sentimentos devem ser organizados de modo a ir construindo vínculos e caminhos entre a organização líquida e o comportamento muscular. Uma das funções dos sentimentos é comunicar estados organísmicos profundos, como fome, amor, dor. A segunda função dos sentimentos é organizar estados de percepção consciente e ação. Criando continuamente organização buscando expressão, o sentimento torna-se forma. Forma e sentimento são, assim, um continuum da liquidez à solidez, da experiência interna à expressão externa.

Escolas e outras instituições também compreendem essa conexão. Elas nos ensinam que, para prestar atenção, nossos sentimentos devem ser silenciados, para possibilitar concentração em uma autoridade externa. Essa forma é criada ficando-se estático, endurecendo o pescoço, focalizando os olhos e firmando a cabeça. Esse fenômeno do continuum de senti- 
mento e forma é o cerne da compreensão da natureza da vida emocional 5 .

A produção cultural foi empurrada para o interior da mente, para dentro do sujeito monádico: já não mais fita diretamente, com seus próprios olhos, o mundo real à procura do referente; como na caverna de Platão, ela é forçada a buscar as suas imagens mentais do mundo nas paredes de seu confinamento. O realismo que nos resta é um "realismo" que decorre da captação chocante deste confinamento e da consciência viva de que, por motivos especiais de algum tipo, nos vemos condenados a buscar o passado histórico através de nossas imagens pop e de nossos estereótipos a seu respeito. $\mathrm{O}$ próprio passado, no entanto, permanece, para sempre, fora do alcance.

A originalidade do pensamento de Lacan neste campo está no fato de haver considerado a esquizofrenia substancialmente uma desordem de linguagem associando-a a toda uma teoria da aquisição da linguagem como o elo esquecido da concepção freudiana da formação do psiquismo adulto. Para tanto, ele nos dá uma versão lingüística do complexo de Édipo, segundo a qual a rivalidade edipiana é interpretada não em termos do indivíduo biológico, o rival das atenções maternas, mas em termos daquilo que ele chama Nome-do-Pai, a autoridade paterna agora considerada função lingüística. O que precisamos extrair disso é a idéia de que a psicose e mais particularmente a esquizofrenia se formam a partir da deficiência infantil em ascender plenamente ao domínio da fala e da linguagem.

Quanto à linguagem, o modelo lacaniano é um modelo estruturalista ortodoxo, baseado em uma concepção do signo lingüístico dotada de dois (ou talvez três) componentes. Um signo, uma palavra, um texto são aqui modelizados conforme o relacionamento de um significante - uma materialidade, o som de uma palavra, a escrita de um texto - com um significado, o sentido da materialidade da palavra ou do texto. O terceiro componente seria o assim chamado "referente", o objeto "real" do mundo "real" ao qual o signo remete - o gato ou o som do gato. Ocorre, porém, que existe em geral no estruturalismo uma tendência de tratar esta referência como uma espécie de mito, de tal modo que ninguém possa mais falar sobre o "real" de forma objetiva e exterior. Assim, o que nos resta é o próprio signo e seus dois componentes. Ao mesmo tempo, o estruturalismo trata de refutar a velha concepção da linguagem como nomeação (e.g. Deus deu a linguagem a Adão com a finalidade de nomear os animais e as plantas do Éden), a qual envolve uma correspondência termo-a-termo de cada significante com cada significado. Ao adotar uma visão estrutural, com razão notamos que frases não funcionam desse modo: não traduzimos uma a uma as palavras ou significantes em termos de seu significado. Pelo contrário, o que lemos é a frase inteira, e é do inter-relacionamento de suas palavras ou significantes que se deduz uma significação mais global - denominada agora um "efeito-de-sentido". O significado talvez mesmo a ilusão ou a miragem do significado e do sentido em geral - é um efeito produzido pelo inter-relacionamento das materialidades significantes.

Tudo isso nos coloca em condições de compreender a esquizofrenia como um distúrbio do relacionamento entre significantes. Para Lacan, a experiência da temporalidade, da temporalidade humana (passado, presente e memória), a persistência da identidade pessoal através de nomes e anos - a própria sensação vivida e existencial do tempo - são também um efeito da linguagem 6 .

A construção do sujeito se faz portanto dentro de um contexto social. O sujeito como membro ativo do seu processo. Vivendo uma dinâmica interacional entre ele e o seu meioambiente. Os valores vivenciados nas manifestações culturais são elementos constitutivos e valores que manterão essa dinâmica viva. Reconhecer o outro na sua potencialidade e no seu processar histórico. O indivíduo é fazedor do seu processo individual ao mesmo tempo em que é também coletivo. É sustentado por valores significantes, próprios da sua cultura, e assim ele se constrói, contribuindo para a construção do social. Desconhecer esse processo de fazer o indivíduo, oferecer elementos de significado como significante para o seu desenvolvimento individual, e ofertar um ambiente de possibilidades esquizofrênicas. Um ambiente que coisifica o indivíduo, em que ele mesmo contribui para o seu desenvolvimento e dos valores sociais, é um meio absolutamente distorcido. O ser humano é um sujeito de histórias, de temporalidade, de significantes e significados, sua objetivação é construída dentro dos valores vividos num plano ético, moral e social. $\mathrm{O}$ indivíduo é fruto e é semente, e esta objetivação dialoga com a subjetivação. O propósito de fazer algo, de construir algo, de consultar um doente, perpassa naturalmente pelas histó- 
rias de cada um. E, neste exato momento de uma consulta, estamos diante de uma construção, que Prigogine intitulou de estruturas dissipativas. Isto quer dizer que, quando duas atividades, duas funções distintas ou mesmo quando duas pessoas se encontram, como acontece numa relação terapêutica, essa interligação vai possibilitar outras interligações absolutamente novas, que, por sua vez, emitirão padrões de probabilidades de um fato poder acontecer. Estamos diante de um fato que não se sabe com certeza as respostas, nem os resultados. Mesmo que este terapeuta tenha mais de 30 anos de atividades profissionais, sempre que ele se depara com um novo cliente, ele estará diante de probabilidades. E são estas probabilidades que são respaldadas pelas historicidades destes dois elementos frente a frente.

Diferentemente disso, o fetichismo da mercadoria e a reificação das relações sociais constituem a forma objetiva do ser social no mundo do capital. Por isso, a sua existência sóciohistórica independe da consciência que os indivíduos possam ter desses fenômenos. A ordem social burguesa possui uma aparência de algo dado desde sempre, de um conjunto inorgânico e justaposto de coisas isoladas e independentes umas das outras e especialmente dos homens, que escapa ao controle de todos e a que o indivíduo deve se adaptar para "viver". As relações sociais são vividas e percebidas como um processo inatingível em seu sentido e em sua dinâmica, exatamente pelas probabilidades (acréscimos do autor). O mundo social institucionalizado dirige a existência humana como instância alheia, incógnita e impessoal, uma aparência de inexorabilidade e fatalidade dos processos de produção e reprodução da vida social $^{3}$.

Isso corre exatamente porque, com a cultura de massas que se produz com a hipertrofia e difusão extraordinária dos meios de comunicação de massa, temos a ampliação do fenômeno da reificação que penetra em todas as dimensões e interstícios da vida social, abrangendo tanto as suas instituições constitutivas quanto as suas esferas imaginárias e simbólicas. A cultura de massa transformou a imagem em significante material de primeira grandeza em nossa sociedade 3 .

Assim, o sujeito da troca é também tão abstrato, formal e reificado como o seu objeto. A ciência perde a capacidade de compreender a origem e o desaparecimento, o caráter social da sua própria matéria, assim como o caráter so- cial das tomadas de posição possíveis a seu respeito e a respeito do seu próprio sistema formal. Nas crises, o ser qualitativo das "coisas" que vive uma vida extra-econômica como coisa em si, incompreendida e eliminada como valor de uso que tranqüilamente julgamos poder desprezar durante o funcionamento normal das leis econômicas, torna-se subitamente (claro que para o pensamento racional e reificado) o fator decisivo ${ }^{7}$.

No entanto, é possível que seja mais fácil abordar o esmaecimento do afeto por meio da figura humana, e é óbvio que o que foi dito a respeito da transformação dos objetos em mercadoria aplica-se com a mesma força às figuras humanas de Warhol: estrelas - como Marilyn Monroe - que se tornam mercadorias e se transformam em sua própria imagem. E também aqui um retorno abrupto ao período mais antigo do alto modernismo nos oferece uma parábola emblemática da transformação em questão. O quadro O grito, de Edvard Munch, certamente é uma expressão canônica dos grandes temas modernistas da alienação, da anomia, da solidão, da fragmentação social e do isolamento - um emblema programático virtual do que se costuma chamar a era da ansiedade.

Todas essas questões nos levam inevitavelmente a um dos temas mais em voga na teoria contemporânea, o da "morte" do próprio sujeito - o fim da monâda, do ego ou do indivíduo autônomo burguês - e a ênfase correlata, seja como um novo ideal moral, seja como descrição empírica, no descentramento do sujeito, ou psique, antes centrado 8 .

Todo médico especialista deve admitir que, às vezes, convenceu pacientes a passarem por procedimentos diagnósticos ou terapêuticos em alguma fase da doença, tão irracionalmente, que seria melhor que o Enigma tivesse permanecido sem solução. Muitas vezes próximo do fim, se o médico fosse capaz de lançar um olhar profundo para dentro de si mesmo, reconheceria que suas decisões e orientações são motivadas pela incapacidade de desistir do Enigma e admitir a derrota enquanto houver qualquer chance de decifrá-lo. Embora seja bondoso e atencioso com seu paciente, ele se permite esquecer sua bondade, pois a sedução do Enigma é tão forte e sua incapacidade de decifrá-lo torna-o tão fraco ${ }^{9}$.

Acredito que a crescente mecanização e "estupidificação" da maioria dos processos de manufatura envolvem o grave perigo de uma de- 
generação geral de nosso órgão da inteligência. Quanto mais as oportunidades de vida do trabalhador inteligente e do apático se equipararem pela repressão das habilidades manuais e disseminação do trabalho maçante e enfadonho na linha de montagem, mais um bom cérebro, mãos habilidosas e um olho aguçado se tornarão supérfluos. De fato, o homem sem inteligência, que naturalmente acha mais fácil se submeter à labuta enfadonha, será favorecido; é provável que ele ache mais fácil prosperar, estabelecer-se e gerar a descendência. $O$ resultado poderá facilmente elevar-se até uma seleção negativa no tocante aos talentos e dons ${ }^{10}$.

\section{Considerações finais}

Para podermos pontuar algumas considerações finais, pois o tema requer um debruçamento mais aprofundado, podendo ir mais além do que abordamos neste artigo. Para tanto, muitos já efetivamente deram o pontapé inicial desde Marx.

O oceano de sensações oriundas dos ritmos da pulsação é nossa matriz, uma geometria que as células de cérebro organizam em configurações que representam os níveis pré-pessoal (a fase da criança), social (a fase do adulto coletivo) e pessoal (a fase do adulto indivíduo).

A pulsação é o self básico. É uma corrente ondulante que gera desejos, sentimentos, idéias, ações. Pulsação é uma herança pré-pessoal. Ela ergue uma camada externa numa membrana e continente, separando o exterior do interior. Desse modo, a corrente estratifica-se e o exterior pode falar com o interior. Nasce assim o feedback, diálogo. Emerge a dimensão humana. O exterior em diálogo com o interior cria uma resposta que estabiliza nossas associações e memórias, conceitos e ações e nos dá um senso de pessoal. Essa formação de um self individual é uma operação monumental. Formação de outra camada regula uma existência dual e personifica a vida impessoal. Temos agora uma tríade em vez de díade 5 .

A imagem somática é uma forma anatômica ou comportamental. Os músculos esqueléticos são responsáveis pela postura, papéis sociais aprendidos e gestos instintivos. Eles compõem um leque de sensações que criam uma imagem corporal, uma imagem somática externa. Os padrões de motilidade visceral fazem surgir sensações que estabelecem uma imagem somática interna.

Toda imagem somática tem tanto um aspecto interno quanto externo. Há uma parte voltada para o mundo e outra que só se pode reconhecer do interior.

Imagens internas e externas comunicam-se, embora muitas vezes as separamos por negação e conflito, como expomos neste capítulo as questões da objetivação, do fetichismo, da alienação e da reificação. A imagem somática, então, compreende sensações orgânicas internas e configurações emocionais, assim como posturas corporais e atitudes. Uma imagem somática mostra não apenas o universo que somos, mas também revela quem sou, e quem você é 5 .

Todos nós procuramos conexão com sentimentos profundos que dão à vida significado $\mathrm{e}$ valor. O processo somático revela o transcendente, uma existência celular organiza anatomia em verdade emocional, verdade vivida. Vamos da paixão e do desejo à união e à devoção, de uma ordem instintiva a uma ordem social, de uma ordem pessoal à divina. Nós, como seres vivos, manifestamos os mistérios do ser humano. Geramos experiência e as organizamos em configurações temporais, a geometria pela qual o humano, o pessoal, o universal são revelados 5 . 


\section{Referências}

1. Marx K. Manuscritos econômicos-filosóficos e outros textos escolhidos. 4a ed. Vol. 1 e 2. São Paulo: Nova Cultural; 1987. (Coleção os Pensadores).

2. Weber Max. Os três tipos puros de dominação legítima. In: Cohn G, organizador. Weber: sociologia. São Paulo: Ática; 1997. p.128-41. (Coleção Grandes Cientistas Sociais, 13)

3. Evangelista JE. Elementos para uma crítica da cultura pós-moderna. Novos Rumos 2001; 16(34):7-35.

4. Favre R. Apresentação da obra de Stanley Keleman In: Keleman S. Anatomia emocional. São Paulo: Summus Editorial; 1995.
5. Keleman S. Corporificando a experiência. São Paulo: Summus Editorial; 2002.

6. Jameson F. Pós-modernidade e sociedade de consumo. Novos Estudos CEBRAP 1985; 12:101-45.

7. Marx K. O capital: crítica da economia política. (Cap. 1-A Mercadoria). São Paulo: Abril Cultural; 1984.

8. Jameson F. Pós-modernismo. A lógica cultural do capitalismo tardio. São Paulo: Ática; 1996.

9. Castells M. A sociedade em rede. 3a ed. São Paulo: Paz e Terra; 1999. (A Era da Informação: Economia Sociedade e Cultura, 1).

10. Schrodinger E. O que é vida? São Paulo: Ática; 1997.

Artigo apresentado em 25/11/2004

Aprovado em 12/05/2005

Versão final apresentada em 12/05/2005 